\title{
Influence of Social Power and Distance on Request Strategies in Saudi Arabic
}

\author{
Jalal Almathkuri \\ English language Centre, Taif University \\ Taif, Kingdom of Saudi Arabia \\ E-mail: jalmathkuri@gmail.com
}

Received: March 25, 2021

Accepted: June 8, 2021

Published: June 17, 2021

doi:10.5296/ijl.v13i3.18770

URL: https://doi.org/10.5296/ijl.v13i3.18770

\begin{abstract}
The aim of this study is to investigate the impact of social power and distance on the strategies involved in performing the speech act of request by native speakers of Saudi Arabic. The participants of this study are 26 males and 8 females; all are undergraduate students enrolled in different disciplines at Taif University, Saudi Arabia. Data for this study was collected through the use of a Discourse Completion Task (DCT). The results revealed that the direct strategy is the most preferred strategy employed in making requests by Saudi Arabic native speakers and the nonconventional indirect strategy is the least strategy. It is hoped that this study will facilitate the acquisition of Saudi Arabic pragmatics by non-native speakers in a way to eliminate the miscommunications they may encounter in relation to the sociocultural norms.
\end{abstract}

Keywords: Requests, Saudi Arabic, Social power, Social distance, Speech acts

\section{Introduction}

To acquire a language is not simply to acquire its phonological, morphological, syntactic and lexical systems; very essential is to acquire its sociopragmatic rules as well. Such kind of knowledge will enable the learner to interact appropriately with native speakers, especially when it comes to a performance governed by social or cultural norms. In the Kingdom of Saudi Arabia (KSA, henceforth), English as a foreign language (EFL) is taught in schools and universities with little focus on sociopragmatic rules which, as a result, leads to committing sociopragmatic mistakes when communicating with native speakers of English. Such mistakes may hinder communication or lead to being viewed as impolite by listeners. Teachers of English need to focus on how to perform speech acts in the target language and 
this requires understanding speech acts in the learners' native language as well in order to show the similarities and differences between the norms of the two cultures: learners' culture and target language culture, Arabic and English in this case. Few studies have investigated this issue constituting a gap in the existing literature. Moreover, a lot of foreigners live and work in most of the Saudi cites, Taif is no exception. These foreigners need to communicate with native speakers of Saudi Arabic, so being unaware of how speech acts are performed in Saudi Arabic (SA, henceforth) in accordance with the Saudi social and cultural norms constitutes a problem for them. Therefore, the need for the present study arises.

Pragmatics is the study of the intended meaning; it is concerned with what the speaker means by his or her utterance rather than the meaning of the individual words they use. One of the sub-fields of pragmatics is sociopragmatics which is, according to Crystal (2008), "A term sometimes used within the study of pragmatics, to refer to the way conditions on language use derive from the social situation" (p. 441). Leech (1983) divided the areas of pragmatics into three categories (1) general pragmatics "the general conditions of the communicative use of language" (p. 10); (2) pragmalinguistics which is concerned with "the particular resources which a given language provides for conveying particular illocutions" (p. 11); and (3) sociopragmatics which focuses on "more specific 'local' conditions on language use" (p. 10). Sociopragmatics considers the beliefs of the speakers and hearers according to the norms of their societies and cultures. It investigates the socio-contextual effects on language as social actions. In this area of pragmatics, linguists focus on the different relationships that exist between the aspects of language use and the socio-cultural rules and practices of the speech community of that language. The relationships between the three mentioned-above areas of pragmatics were presented in a diagram by Leech $(1983$, p. 11). This diagram is shown in Figure 1 below.

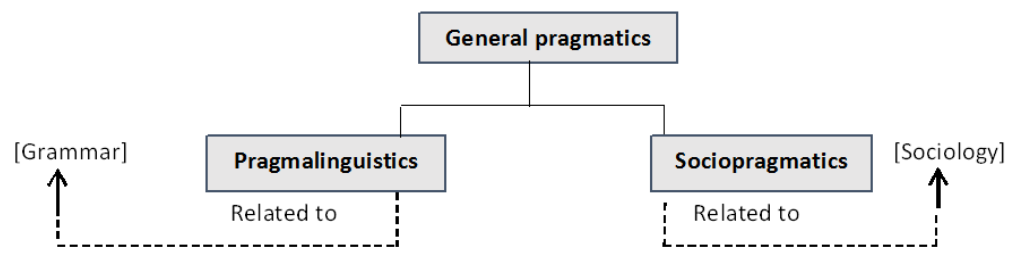

Figure 1. Areas of pragmatics (Leech, 1983, p. 11)

Language and culture are two concepts that are interwoven in the sense that language is an instrument for preserving and transforming culture, whereas the influence of culture on language is very obvious in the language of any speech community. Exploring the extent to which the sociocultural norms of a particular society impact the use of language has attracted the attention of many researchers (e.g., Yaqubi et al, 2016; Maer, 2015, Samarah, 2015; Alrefai, 2012, among others). Pragmatic research has focused on how sociocultural norms influence the language to explore the ways in which these rules are acquired in order to facilitate communication (Al-Adaileh, 2007).

In communication, there are utterances used to achieve certain communicative actions; they are referred to as speech acts. The term 'speech acts' has been defined by Searle (1976) as 
"the basic minimal units of linguistic communication" (p. 16). The study of speech acts offers a perception of the social and linguistic norms of the speech community of the language being studied (Meier, 1997; Olshtain \& Blum-Kulka, 1985). Speech act studies have focused on requests, suggestions, apologies, refusals, complaints, etc. The focus of this study is on requests performed by Saudi native speakers. Being unaware of how to perform speech acts in the target language may hinder communication as Rubin (1989) put it "lack of knowledge of speech act realization patterns and strategies across cultures can lead to breakdowns" (p. 12). Therefore, investigating the production of speech acts, including requests, is an important instrument for yielding more information about the culture of the native speakers in terms of pragmatic norms.

According to the focus of speech acts' studies, there are four different areas investigated by researchers: learner-focused studies which investigate how learners acquire and develop their pragmatic knowledge in the target language (e.g., Thomas, 1995), methodological studies with a concern about data collection methods (e.g., Yuan, 2001), cross-cultural studies interested in making comparisons between the speech acts in two or more cultures (e.g., Blum-Kulka \& Olshtain, 1984), and intralingual studies in which speech acts are investigated in a single language or culture (e.g., Farghal \& Haggan, 2006; Demeter, 2007; Nureddeen, 2008; Amer et al., 2020a, 2020b, 2020c).

Investigating the speech act of requests only in SA makes this study an intralingual one. It attempts to investigate the speech act of requests in SA. More specifically, it examines whether the performance of requests in the Saudi variety of Arabic is affected by power or social distance. So, the main objective is to find the strategies of politeness used while performing the speech act of requests and map them on the social variables of power and distance.

\section{Literature Review}

Requests, as a component of everyday communication, is a central issue in politeness research (Uso-Juan, 2010); they are referred to as pre-event acts since they result in an action in the event (Blum-Kulka \& Olshtain, 1984). Requests are also classified as face-threatening acts (FTAs) because they involve a threat to the interlocutors' face (Yule, 1996). Moreover, they are classified into two major groups: direct and indirect requests (Searle, 1979). The direct requests are the acts which do not require any inference on the part of the listener; they can be understood clearly so they are, according to Austin (1962, p.99), 'locutionary acts'. On the other hand, the indirect requests are 'illocutionary acts' for they require the listener's inference in order to understand the intended meaning of the speaker (ibid). Once the interlocutors share cultural and social backgrounds, such illocutionary acts are easily interpreted, otherwise, communication will be difficult and may lead to misunderstanding between the interlocutors (Eslami \& McLoed, 2010).

As the name suggests, a direct request can be easily understood by the listener, so it is easy for him or her to evaluate and respond to it whether positively or negatively. On the other hand, Searle (1975) believed that an indirect request will have two meanings: literal meaning and pragmatic meaning. The literal meaning refers to the meaning of the individual words 
and the grammatical form of the sentence, whereas the pragmatic meaning refers to the meaning intended by the speaker regardless of the meaning of the individual words that constitute the sentence. For instance, when someone says 'It is hot inside this room.', if the hearer relies on the meanings of the individual words and the form of the sentence, he or she will consider it a statement for which s/he may say 'Yes, it is.', 'No, it is not.', or may provide no comments at all. On the other hand, relying on the pragmatic meaning, s/he may say 'I'll open the window.' or 'I'll turn the air conditioner on.'

Sociopragmatic researchers may investigate the linguistic behaviours of people during their daily interactions when they perform speech acts such as requests, compliments or responses, and the politeness strategies they use to express themselves within the norms of their societies. Because people use different strategies of politeness in accordance with their societies (Huang, 2008), this study tries to explore the various politeness strategies employed in the use of requests by SA native speakers of both genders in an attempt to facilitate the acquisition of SA by non-native speakers. In addition, being an intralingual study, it may provide a solid ground for pedagogical purposes for a future research on this or any other dialect of Arabic whether as a first or foreign language.

Various speech acts have been investigated by scholars aiming to explore the way learners of foreign or second languages develop their sociopragmatic competence in another language. For example, the pragmatic development of learners of English as a second or foreign language was investigated by a number of researchers; Chinese learners (e.g., Cheng, 2005), and Iranian learners (e.g., Ahar \& Eslami, 2011; Farnia \& Suleiman, 2009). Cui (2012) investigated the speech act of thanking performed by Chinese, Korean, Indonesian and Japanese advanced learners of English as a second language in an attempt to find out the impact of their first languages while performing this speech act. Other studies investigated speech acts cross-culturally - interlingual studies; they made comparisons of certain speech acts in two or more cultures (e.g., Al-Adaileh, 2007; Al-Momani, 2009; Aubed, 2012; Mohammadi \& Tabari, 2013; Abushihab, 2015; Massud, 2016; S. Alqahtani, 2015; Alsalem, 2015; Hassall, 1999; Qari, 2017).

As far as the current study is concerned, there are a few intralingual Arabic studies conducted in this field in which researchers focused on a single Arabic speech community. For example, Farghal and Al-Khatib (2001), Farghal and Haggan (2006), Hahn (2006), Demeter, (2007), Nureddeen (2008), Kuhi and Jadidi (2012), Al-Amro (2013), A. Alqahtani (2015), Altayari (2017), and Amer et al. (2020a, 2020b, 2020c). Among the intralingual studies that investigated request strategies in languages other than Arabic are Ninomiya and Shadayeva (2020), Nezami and Shirkhani (2020), and Wibowo and Cempaka (2020). Ninomiya and Shadayeva (2020) investigated how requests are realized by native speakers of Kazakh and native speakers of Japanese. The results of the study revealed that the Japanese participants used indirect strategies more that the Kazakh participants especially when the social distance between the interlocutors is small, whereas the Kazakh participants used the imperative form of verbs in their requests more that the Japanese ones. Nezami and Shirkhani (2020) studied the request strategies employed by Persian couples in two different settings, namely, private mode and public mode. They recorded the interactions of 30 Persian couples in the two 
settings. The results of the study showed that Persian couples prefer direct strategies when requesting each other in their loneliness, whereas the conventional indirect strategies are employed when other people are present. It was suggested that the presence of other people plays an important role in the couple's choice of the request strategy. Wibowo and Cempaka (2020) classified the speech acts and the request strategies realized in the dialogues of the characters in 'Tall Girl' movie. As for the request strategies, the analysis of the dialogues revealed that they are in mood derivable, explicit performative, hedged performative, locution derivable, want statement, suggestory formulae and query preparatory, almost all Blum-Kulka's et al. (1989) request strategies. However, the authors found that the mood derivable strategy was the most frequently used one. Since the current study focuses on the speech act of requests in a single language, SA, it can be classified as an intralingual study.

In the Saudi context, some researchers compared speech acts in SA and English. For instance, Alsalem (2015) studied the speech act of compliments in SA and American English, S. Alqahtani (2015) compared the use of refusals by SA native speakers and American English native speakers, and Qari (2017) investigated requests and apologies in SA and British English. Intralingual studies of speech acts carried out on SA are rare. However, a few studies are conducted in this area such as Al-Amro (2013) who studied compliments in Najdi SA, A. Alqahtani (2015) who studies 'favour asking' as a speech act in SA, Al-Aqeel $(2015,2016)$ who investigated requesting behaviour in SA, Alateeq (2016) studied refusals, and Altayari (2017) who explored the speech act of apology in SA. The following is a review of the studies related to the present study.

A. Alqahtani (2015) investigated the speech act of favour asking in SA in order to find out the extent to which social distance and power among other factors have influence on the shape of the speech act of favour asking. The author also compared this speech act in SA with Kuwaiti Arabic and American English. Using discourse completion test (DCT), she analyzed the requests of favour made by 60 Saudi female students majoring in English at a university in Riyadh, Saudi Arabia. They were all native speakers of SA. The results of the study showed that the speech act of favour asking was mostly performed by the direct and conventionally indirect strategies in SA, whereas the nonconventional strategies were not preferred by the participants of the study. The results also revealed that the social power had an influence on the strategies used by the participants, whereas the social distance had no influence. When the favour asking act in SA was compared with that in Kuwaiti Arabic and American English, it was found that it is more similar to that in Kuwaiti Arabic than that in American English.

Al-Aqeel (2016) studied the speech act of requests in SA made by Saudi females. Using the role play method and questionnaire, the researcher collected data from 101 participants. The study focused on the influence of the social variables of gender of the hearer, social distance and power on the requests of Saudi females. Using Brown and Levinson's model of politeness for the classification of requests, the results revealed that the direct strategies were preferred by the participants. The results also showed that the social variable of social distance was the most influential factor in having an impact on the requesting behaviour of the Saudi women. As for the gender of the hearer variable, the results indicated that it was obvious in distant relationship through the preference of negative politeness or opting out 
strategies.

Qari (2017) studied the speech acts of requests and apologies made by SA native speakers and compared them with those produced by Saudi EFL learners and British native speakers. The author used DCT to collect data from 160 participants who are university students; 40 males and 40 females are Saudi students. Using Brown and Levinson's (1987) model of politeness, the author analyzed the data. The results of the study showed that Saudi males and females used direct strategies in making requests when compared with other groups who preferred using the indirect ones. Another finding is that Saudis employ a large number of modifiers including religious softeners and prayers. The author concluded that the use of directness by the Saudis indicates that it does not equate impoliteness. The results of the study also showed that there are some gender differences between Saudi males and females in using these speech acts: Saudi males often used direct strategies more than Saudi females when performing a request and such strategies are accompanied by a large number of religious softeners and supportive moves. The author concluded that the reason for the choice of direct strategies could be attributed to the participants' preference of giving out straight-to-the-point instructions in a way to make their intensions of making the act clear to the requestee so that it is not out of impoliteness.

\section{Methodology}

\subsection{Site and Participants}

This intralingual kind of research explores the way the speech act of requests is performed in SA. It focuses on the relationships between requests and two social variables: power and distance in the performance of male and female native speakers of SA. All participants are undergraduate students studying in different disciplines at Taif University; they were randomly chosen from different classes. The total number of participants is 34: 26 males and 8 females. The reason for choosing Taif University as the site of the study is that participants are of similar ages since age has not been included as a variable in this study. All of them are native speakers of SA. Another reason is that the researcher is working at this university, so it was easy for him to get a permission to conduct this study on this particular site.

\subsection{Data Collection}

Data for this study were collected through the use of a Discourse Completion Task (DCT). DCTs are either written or spoken situations designed according to the purpose of the study; they are used by researchers to elicit information from the respondents who are expected to produce what they consider to be appropriate in each situation. DCTs were introduced by Blum-Kulka (1982a, 1982b); they are useful in that the researcher may collect data from large number of participants in different situations while the desired variables are controlled (Kasper, 2000).

In this study, DCT consists of 12 situations; each situation elicits a request to be filled in by the participant who plays the role of the speaker. The situations are meant to gather information on the performance of requests in relation to two social variables: power and distance. Power $(\mathrm{P})$ is the social status of the speaker in relation to the hearer. In this way, 
when the speaker has a higher status than that of the hearer, power variable is $+\mathrm{P}$, when less, $-\mathrm{P}$, and when equal, =P. Distance (D), on the other hand, mirrors the degree to which the speaker and the hearer know each other. It is marked $+\mathrm{D}$ when they are unfamiliar to each other and -D when familiar.

The situations of the DCT of the current study were designed in a way to elicit request strategies for each possible combination of power and distance. The adequacy of the situations and whether they fit into the Saudi cultural and social norms were checked by two SA native speakers in addition to the fact that the researcher himself is a native speaker of this variety of Arabic.

\subsection{Data Analysis}

Data were analyzed using the categories established by Blum-Kulka et al. (1989, p. 18) for classification of requests strategies. There are nine request strategies classified under three broad categories: direct, conventional indirect, and nonconventional indirect strategies. These strategies with their definitions and some examples are presented in table 1 below.

Table 1. Blum-Kulka's et al. (1989) request strategies

\begin{tabular}{|c|c|c|}
\hline Strategy & Definition & Example \\
\hline \multicolumn{3}{|l|}{ Direct strategies } \\
\hline 1. Mood derivable & $\begin{array}{l}\text { The request is indicated by the } \\
\text { grammatical mood of the verb. }\end{array}$ & Help me with my computer. \\
\hline 2. Performative & $\begin{array}{l}\text { The request is explicitly } \\
\text { named. }\end{array}$ & $\begin{array}{l}\text { I am asking you to move this } \\
\text { chair. }\end{array}$ \\
\hline 3. Hedged performative & $\begin{array}{l}\text { The request is modified by } \\
\text { hedging. }\end{array}$ & $\begin{array}{l}\text { I would like to ask you to give } \\
\text { me more time to submit my } \\
\text { assignment. }\end{array}$ \\
\hline 4. Obligation statement & $\begin{array}{l}\text { The hearer's obligation to carry } \\
\text { out the task is explicitly stated. }\end{array}$ & $\begin{array}{l}\text { You will have to come on } \\
\text { Monday. }\end{array}$ \\
\hline 5. Want statement & $\begin{array}{l}\text { Indicates the speaker's desire } \\
\text { that the hearer perform the } \\
\text { task. }\end{array}$ & $\begin{array}{l}\text { I really wish you'd postpone the } \\
\text { exam. }\end{array}$ \\
\hline \multicolumn{3}{|c|}{ Conventional indirect strategies } \\
\hline 1. Suggestory formulae & $\begin{array}{l}\text { The speaker makes a } \\
\text { suggestion for the hearer to } \\
\text { perform the task. }\end{array}$ & How about typing this letter? \\
\hline 2. Query preparatory & $\begin{array}{l}\text { The speaker inquires about the } \\
\text { possibility of carrying out the } \\
\text { request by the hearer. }\end{array}$ & Can you open the window? \\
\hline \multicolumn{3}{|c|}{ Nonconventional indirect strategies } \\
\hline 1. Strong hints & $\begin{array}{l}\text { Explicit reference to an object } \\
\text { necessary for completing the } \\
\text { task is made. }\end{array}$ & You left the door open. \\
\hline
\end{tabular}


2. Mild hints

No reference is made to any 'I am a nun' - in response to a needed object, but it can be persistent hassle.

interpreted as a request

according to the context.

\section{Findings and Discussion}

Based on the assumed relations between the participants in the designed situations of this study, three different categories are established according to the distance and power relationships: equity of the power variable and absence of the distance variable (=P and $-D)$, equity of the power variable and presence of the distance variable $(=\mathrm{P}$ and $+\mathrm{D})$, and presence of the power variable on the part of the requestee and presence of the distance variable (-P and $+\mathrm{D})$.

\subsection{Equal Power and No Social Distance $(=P \&-D)$}

In this category the two social variables of distance and power are equal between the requester (the speaker) and the requestee (the hearer), so they are socially equal and having the same power over each other. The situations that fall under this category are Situation 1, 2, and 6 . The researcher found some common strategies which are used by both genders and some other strategies used only by male-participants. The female-participants did not show any special strategies, so all the strategies they employed were also employed by the male-participants.

As for the common strategies, the participants employed two types of direct strategies and two types of conventional indirect strategies.

According to their responses to the designed situations, the participants employed two types of direct strategies: mood derivable and want statement strategies. In mood derivable, they indicated their requests by the use of the imperative form of the verb. For example, in response to Situation 1, the female-participant number 2 (F2) uses the verbs خذ/xøð/ 'take' and وزع/wazzIS/ 'distribute' the latter is also used by the male-participant number 4 (M4) and M25, and the verb ساعدني/sa:SIdnI/ 'help me' as used by M15 in response to Situation 1. However, in response to Situation 2 and 6, female-participants did not use this strategy whereas male-participants employed it by using the imperative verbs جدا /dzaddId/ 'renew' by M20 and عطني / ع / عatnI/ 'give me' as used by M17 and M23. Want statement was indicated in all situations in this category by the structure ابغى/2abra/ or / أبي /Pabl/ 'I want' as used by F5 and M8 in response to situations 1 and 2 respectively.

In the conventional indirect strategies, the participants used suggestory formulae and query preparatory sub-strategies. Using the first sub-strategy, they indicated their requests by making a suggestion for the hearer to perform it using the formula ايش رايك /PIfra:jak/ 'how about' employed by F5 and M13 giving an option to the hearer in Situation 2 to refuse performing that request, whereas with the second sub-strategy they inquired about the possibility of performing the request by the hearer using two frequent structures: ممكن Imumkin/ 'if it is possible' as used by F6 in response to Situation 2, and by M19 and M24 in response to Situation 1. The second structure is the use of قدر//Ragdarl 'can I' which is used in 
response to Situation 6 by the participants: F1, F5 and M16.

Under this category where distance and power are equal among the interlocutors, the researcher found that two sub-strategies are used only by male-participants which are performative: using أبيك/2abr:k/ 'I want you to' (M13 S1) and hedged performative.

\subsection{Equal Power and Social Distance $(=P \&+D)$}

It is not always true that people who work or study together are well-known to each other although they might have been working or studying in the same organization for some time. In this category the distance variable exists which means that the requester and the requestee are not familiar to each other, and they have no power over each other; it is equal. The situations that fall under this category are Situation 3, 4, and 8.

Male-participants and female-participants employed four sub-strategies: three direct ones and one conventional indirect sub-strategy. The direct strategies include mood derivable which is seen in responses to Situation 4 by a number of female and male participants. For example, F8 and M9 employed this strategy by using the verbs قوم /gu:m/ 'leave', whereas M11 used the imperative بعد /2IbGId/ 'move' in response to Situation 4. The strategy of hedged performative was shown by F8 and M16 in response to Situation 8; want statement was employed using the verb ابغى /Pabral 'I need' by F3 and M8 in response to Situation 8 and 4 respectively, whereas M9 used the structure حبيت / حabbeIt/ 'I wish' responding to Situation 8. The male-participants employed the mood derivable sub-strategy using some imperative verbs that were not used by female-participants such as the verb رجع/radzdzIS/ 'take back'

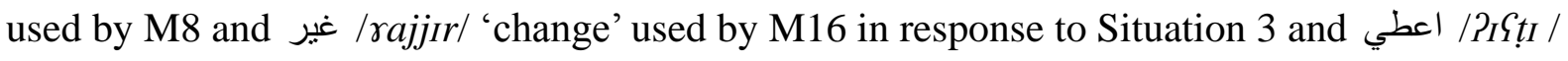
'give' used by M6 in response to Situation 8. Moreover, male-participants employed the

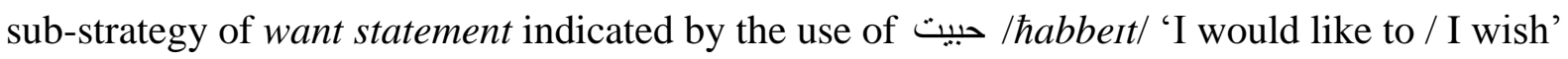
(M9, M10) and أريد /Parı:d/ 'I want' (M14, M20) in response to Situation 3, whereas the female-participants did not use any of these sub-strategies in their responses to Situation 3 and 8. The conventional indirect sub-strategy is the query preparatory; it is used with no gender differences. However, it is indicated by two frequent structures asking about the possibility of doing the act. First is the use of 'if it is possible' indicated by مكن /mumkın/ as used by F2 and F4, and the structure اذا ممكن/2Iða mumkın/ by M8 and M14 in response to Situation 6. Second is the use of قدر /2agdar/ 'can I' by F1 and F5 responding to Situation 6, and يمديك /jImdr:k/ or تقر /tigdarl 'can you' as used by M5 and M7 respectively in response to Situation 1.

\subsection{Different Power and Social Distance $(-P \&+D)$}

In this category the distance variable exists between the requester and the requestee and the requestee has a kind of power over the requester. The situations that fall under this category are Situation 5, 7, 9, and 10. Like the above two categories, this category includes common strategies and some special ones used by either gender.

In common strategies four sub-strategies are found to be used by both: males and females. Three of them are sub-strategies of the direct strategy and one is a sub-strategy of the conventional indirect strategy. 
The direct strategies include performative which is used in response to Situation 5 using the structure 'I need/want you to' as indicated by أريد منك احتاج منك /Paћta:d3 minnak/ by F5 and /Parı:d minnak/ as used by M16; hedged performative sub-strategy is used by a number of male and female participants such as F4, F5, M10 and M22 in response to Situation 7, and F1 and M17 in response to Situation 10. The third sub-strategy of the direct strategy is want statement which is indicated by ابغى /Pabral 'I want' by F7 and M11 in response to Situation 10 and 5 respectively, حبيت / حيا ليت /ja:lert/ 'I wish' as used in response to Situation 10 by M23.

In response to situations 5 and 7, some participants employed the query preparatory sub-strategy of conventional indirect strategy. In their responses, they used مكن /mumkın/ 'can I/you' (e.g., F2, F6, F8, M10, M18 responding to Situation 5) and اذا امكن/2rða Pamkan/ 'if it is possible' as used in response to Situation 7 by M15 and M19.

Male and female participants used the direct sub-strategy of mood derivable but with some differences. For instance, males used the verbs تمدد/tmadId/ 'extend' in response to situation 5 as used by M3 and M23, the imperative verb منحني/PImnaћnI/ by M15 responding to Situation 5 or the verb عطني/SatnI/ 'give' by M12 in response to Situation 9, and كتب /?uktub/ 'write' as used by M4 and M22 in response to Situation 9. Female-participants, on the other hand, used the verbs ساعديني/ / وافقي /wa:fgII/ 'accept' in response to Situation 10 as used by F8.

Moreover, both males and females employed the query preparatory sub-strategy in response to different situations; for example, male-participants used it in response to Situation 10 whereas female-participants used it in response to Situation 9. Other differences that exist between the two genders in this category include: the male-participants employed the want statement sub-strategy more than the female participants did in that they used it in response to situations 7 and 9; only males made use of the nonconventional indirect strategy as they employed the sub-strategies of strong hints employed by M26 and mild hints which was used by M6 and M11 in response to Situation 5 and 10 respectively. Another gender difference is observed in responding to Situation 9 and 5 where only females employed the performative and hedged performative sub-strategies of the direct strategy respectively.

To sum up, the participants preferred using the direct strategy when power is equal and the conventional indirect strategy when the power is different. This agrees with the findings of A. Alqahtani (2015) that the social power had an influence on the choice of strategies made by her participants. The social distance variable in this study is found to be significant as the participants preferred direct strategies when there is no distance, whereas the conventional indirect strategy is preferred in situations with social distance. This preference of the direct strategy agrees with the findings of A. Alqahtani (2015), Al-Aqeel (2016) and Qari (2017).

\section{Conclusion}

This study has focused on the impact of the social power and distance on the request strategies performed by native speakers of SA using the categories established by Blum-Kulla et al. (1989) for the classification of requests strategies (see table 1 above). 
Based on the results of the analysis, three different categories are established in relation to the power and distance variables: equal power with no distance, equal power with distance and power on the part of the requestee with distance. In the first category, the participants employed the direct strategy (mood derivable and want statement) and conventional indirect strategy (suggestory formulae and query preparatory). The results showed that two sub-strategies were used only by male-participants which are performative and hedged performative. In the second category, the participants used three direct sub-strategies: mood derivable, hedged performative and want statement, and one type of the conventional indirect sub-strategy (query preparatory). The third category has included the use of three direct sub-strategies (performative, hedged performative and want statement), and one conventional indirect sub-strategy (query preparatory). As for gender differences, only males used nonconventional indirect strategies (strong hints and mild hints). Except for the nonconventional indirect strategy, all other strategies were found to be used by both males and females. However, there are some gender differences in relation to the situations where the strategies were employed (see section 4.3).

As for the power and social distance influence on the participants' choice of the request strategy, the results of the study showed that whether power is equal or not, participants preferred the use of the direct strategy to other strategies except for the use of the nonconventional strategy in the situations where the requestee has a sort of power over the requester. On the other hand, the social distance variable showed more significance in that when there is no social distance between the requester and the requestee, the frequency of the direct strategy is more than that of the conventional indirect strategy, whereas the situations with the presence of social distance showed that the conventional indirect strategy is more employed than the direct one in addition to the use of some nonconventional sub-strategies. This supports the idea that directness in the Saudi society is not considered impoliteness since the participants used it in situations with no social distance so they are making their intensions of the required act clear and straightforward rather than being impolite.

It is hoped that this study will facilitate the acquisition of Saudi Arabic pragmatics by non-native speakers in a way to eliminate the miscommunications they may encounter in relation to the sociocultural norms. In addition to this, further studies are encouraged to be conducted on Saudi Arabic investigating other speech acts such as apology, compliments and greetings in order to have a panoramic picture of the social variables influence on the pragmatics of this Arabic variety.

\section{References}

Abushihab, I. (2015). Contrastive analysis of politeness in Jordanian Arabic and Turkish. Theory and Practice in Language Studies, 5(10), 2017-2022. https://doi.org/10.17507/tpls.0510.06

Ahar, V., \& Eslami, A. (2011). The effect of social status and size of imposition on the gratitude strategies of Persian and English speakers. Journal of Language Teaching and Research, 2(1), 120-128. https://doi.org/10.4304/jltr.2.1.120-128 
Al-Adaileh, B. (2007). The speech act of apology: A linguistic exploration of politeness orientation in British and Jordanian culture. Unpublished PhD Thesis, University of Leeds, UK.

Al-Amro, M. (2013). The sociolinguistics of compliment behaviour in Najdi Saudi Arabic. Unpublished PhD Thesis, Ball State University, Indiana.

Al-Aqeel, H. (2015). Requests in Saudi pidgin Arabic. Business Management and Strategy, 6(1), 111-137. https://doi.org/10.5296/bms.v6i1.7682

Al-Aqeel, H. (2016). Requesting behaviour of Saudi Arabian women in contemporary Arabic-speaking situations. Unpublished PhD Thesis, RMIT University.

Alateeq, E. (2016). Refusal strategies in Saudi Arabian social settings. Unpublished MA Thesis, Southern Illinois University at Carbondale.

Al-Momani, H. (2009). Caught between two cultures: The realization of requests by Jordanian EFL learners. Unpublished PhD Thesis, Indiana University of Pennsylvania, Indiana. PA.

Alqahtani, A. (2015). Favour asking in Saudi Arabic. Unpublished MA Thesis, Oklahoma State University.

Alqahtani, S. (2015). Cross-cultural comparison of Saudi and American students in the speech of refusal. Unpublished MA Thesis, Southern Illinois University at Carbondale.

Alrefai, E. (2012). Favor asking in Kuwaiti Arabic: Effects of power and distance on core strategies and modification. Available from ProQuest Dissertations \& Theses Global: $\begin{array}{lllll}\text { Literature } \& \text { Language. } & \text { Retrieved }\end{array}$ http://search.proquest.com/docview/1039155719?accountid=35493

Alsalem, N. (2015). Compliment responses: A comparison of Saudi English learners and native speakers of American English in an academic environment. Unpublished MA Thesis, Southern Illinois University at Carbondale.

Altayari, D. (2017). A sociolinguistic study of the speech act of apology by Saudi speakers. Humanity \& Social Sciences Journal, $12(2), \quad 37-44$. https://doi.org/10.5829/idosi.hssj.2017.37.44

Amer, F., Buragohain, D., \& Suryani, I. (2020a). Politeness strategies in making requests in Jordanian call-centre interactions. Education and Linguistic Research, 6(1), 69-86. https://doi.org/10.5296/elr.v6i1.16283

Amer, F., Buragohain, D., \& Suryani, I. (2020b). Responding strategies to greetings and invocations in Jordanian Arabic in CCCS interactions: A socio-pragmatic study. European Scientific Journal, 16(8), 62-74. https://doi.org/10.19044/esj.2020.v16n8p62

Amer, F., Buragohain, D., \& Suryani, I. (2020c). Responding strategies in Jordanian Arabic: A socio-pragmatic study. Journal of Scientific Research \& Reports, 26(2), 13-26. https://doi.org/10.9734/jsrr/2020/v26i230220 


\section{I Macrothink}

International Journal of Linguistics

ISSN 1948-5425

2021, Vol. 13, No. 3

Aubed, M. (2012). Polite requests in English and Arabic: A comparative study. Theory and Practice in Language Studies, 2(5), 916-922. https://doi.org/10.4304/tpls.2.5.916-922

Austin, J. (1962). How to do things with words. Oxford, England: Calderon Press.

Blum-Kulka, S. (1982a). Learning how to say what you mean in the second language: A study of speech act performance of learners of Hebrew as a second language. Applied Linguistics, 3, 29-59. https://doi.org/10.1093/applin/3.1.29

Blum-Kulka, S. (1982b). Performing speech acts in a second language. In S. Blum-Kulka, R. Nir, \& Y. Tobin (Eds.), Issues in the study of discourse (pp. 144-177) Jerusalem: Academon.

Blum-Kulka, S., \& Olshtain, E. (1984). Requests and apologies: A cross-cultural study of speech act realization patterns. Applied Linguistics, 5, 196-213. https://doi.org/10.1093/applin/5.3.196

Blum-Kulka, S., House, J., \& Kasper, G. (1989). Cross-cultural pragmatics: requests and apologies. Norwood, NJ: Ablex.

Cheng, S. (2005). An exploratory cross-sectional study of interlanguage pragmatic development of expressions of gratitude by Chinese learners of English. Unpublished PhD Thesis, University of Iowa, Iowa.

Crystal, D. (2008). A dictionary of linguistics and phonetics (6th ed.). Blackwell Publishing Ltd. USA.

Cui, X. (2012). A cross-linguistic study on expressions of gratitude by native and non-native English speakers. Journal of Language Teaching and Research, 3(4), 753-760. https://doi.org/10.4304/j1tr.3.4.753-760

Demeter, G. (2007). Role-plays as a data collection method for research on apology speech acts. Simulation \& Gaming, 38(1), 83-90. https://doi.org/10.1177/1046878106297880

Eslami, Z., \& McLoed, K. (2010). It's 8 o'clock in the morning - are you watching television? Teaching indirect requests. In D. Tatsuki, \& N. Houck (Eds.), Pragmatics from research to practice: Teaching speech acts (pp. 19-28). Alexandria, Virginia: Teachers of English to Speakers of Other Languages, Inc.

Farghal, M., \& Al-Khatib, M. (2001). Jordanian college students' responses to compliments: A pilot study. Journal of Pragmatics 33, 1485-1502. https://doi.org/10.1016/S0378-2166(01)00006-6

Farghal, M., \& Haggan, M. (2006). Compliment behavior in bilingual Kuwaiti college students. International Journal of Bilingual Education and Bilingualism, 9(1), 94-118. https://doi.org/10.1080/13670050608668632

Farnia, M., \& Suleiman, R. (2009). An interlanguage pragmatic study of expressions of gratitude by Iranian EFL learners - A pilot study. Malaysian Journal of ELT Research, 5, 108-140. 


\section{I Macrothink}

International Journal of Linguistics

ISSN 1948-5425

2021, Vol. 13, No. 3

Hahn, J. (2006). Apologizing in Korean. Unpublished PhD Thesis, University of Hawaii, Honolulu, Hawaii.

Hassall, T. (1999). Request strategies in Indonesian. Pragmatics, 9(4), 585-606. https://doi.org/10.1075/prag.9.4.02has

Huang, Y. (2008). Politeness principle in cross-culture communication. English Language Teaching, 1(1), 96-101. https://doi.org/10.5539/elt.v1n1p96

Kasper, G. (2000). Data collection in pragmatics research. In H. Spencer-Oatey (Ed.), Culturally speaking (pp. 316-341). London: Continuum.

Kuhi, D., \& Jadidi, M. (2012). A study of Iranian EFL learners' understanding and production of politeness in three speech acts: Requests, refusal, and apology. Theory and Practice in Language Studies, 2(12), 2624-2633. https://doi.org/10.4304/tpls.2.12.2624-2633

Leech, G. (1983). Principles of pragmatics. London: Longman.

Maer, M. (2015). Intergroup anxiety and attitudes toward Muslims: The effect of religious identity salience and message politeness strategies. Unpublished PhD Thesis, The University of Kansas.

Massud, A. (2016). The (im)politeness aspects of "public complaint" in German and Arabic: A linguistic analysis. Zeitschrift für Angewandte Linguistik, 64(1), 67-95. https://doi.org/10.1515/zfal-2016-0004

Meier, A. (1997). Teaching the universals of politeness. ELT Journal, 51(1), 21-28. https://doi.org/10.1093/elt/51.1.21

Mohammadi, M., \& Tabari, B. (2013). Politeness in Persian and English dissertation acknowledgments. Theory and Practice in Language Studies, 3(8), 1473-1478. https://doi.org/10.4304/tpls.3.8.1473-1478

Nezami, M., \& Shirkhani, S. (2020). Request strategies used by Persian couples in two different settings. Journal of New Advances in English Language Teaching and Applied Linguistics, 2(2), 398-422.

Ninomiya, T., \& Shadayeva, M. (2020). Request strategies in Kazakh and Japanese: A cross-cultural pragmatic analysis. Media Watch, 11(4), 648-667. https://doi.org/10.15655/mw/2020/v11i4/204633

Nureddeen, F. (2008). Cross-cultural pragmatics: Apology strategies in Sudanese Arabic. Journal of Pragmatics, 40(2), 279-306. https://doi.org/10.1016/j.pragma.2007.11.001

Olshtain, E., \& Blum-Kulka, S. (1985). Degree of approximation: Non-native reactions to native speech act behavior. In S. Gass (Ed.), Input in second language acquisition (pp. 303-329). Rowley, MA: Newbury House. 


\section{Macrothink}

International Journal of Linguistics

ISSN 1948-5425

2021, Vol. 13, No. 3

Qari, I. (2017). Politeness study of requests and apologies as produced by Saudi Hijazi, EFL learners, and British English university students. Unpublished PhD Thesis, University of Roehampton, UK.

Rubin, J. (1989). How learner strategies can inform language teaching. In V. Bickley (Ed.), Proceedings from language use, language teaching and curriculum (LULTAC). Hong Kong: Institute of Language in Education.

Samarah, A. (2015). Politeness in Arabic culture. Theory and Practice in Language Studies, 5(10), 2005-2016. https://doi.org/10.17507/tpls.0510.05

Searle, J. (1975). Indirect speech acts. In P. Cole, \& J. Morgan (Eds.), Syntax and semantics (pp. 168-183). New York: Academic Press.

Searle, J. (1976). A classification of illocutionary acts. Language in Society, 5(1), 1-23.

Searle, J. (1979). Expression and meaning. Cambridge: Cambridge University Press.

Thomas, J. (1995). Meaning in interaction: An introduction to pragmatics. London: Longman.

Uso-Juan, E. (2010). Requests: A sociopragmatic approach. In A. Martinez-Flor, \& E. Uso-Juan (Eds.), Speech act performance theoretical, empirical and methodological issues. Amsterdam: John Benjamins Publishing Company.

Wibowo, I., \& Cempaka, G. (2020). Speech act classification and request strategy in "Tall Girl” movie directed by Nzingha Stewart. Lingua, 17(1), 25-34. https://doi.org/10.30957/lingua.v17i1.622

Yaqubi, M., Saeed, K., \& Khaksari, M. (2016). Conversational maxim view of politeness: Focus on politeness implicatures raised in performing Persian offers and invitations. Theory and Practice in Language Studies, 6(1), 52-58. https://doi.org/10.17507/tpls.0601.07

Yuan, Y. (2001). An inquiry into empirical pragmatics data gathering methods: Written DCTs, oral DCTs, field notes, and natural conversation. Journal of Pragmatics, 33, 271-292. https://doi.org/10.1016/S0378-2166(00)00031-X

Yule, G. (1996). Pragmatics. Oxford: Oxford University Press.

\section{Copyrights}

Copyright for this article is retained by the author(s), with first publication rights granted to the journal.

This is an open-access article distributed under the terms and conditions of the Creative Commons Attribution license (http://creativecommons.org/licenses/by/4.0/) 